\title{
n-3 fatty acids from fish and coronary artery disease: implications for public health
}

\author{
Erik B Schmidt ${ }^{1, *}$, Helle A Skou', Jeppe H Christensen ${ }^{2}$ and Jørn Dyerberg ${ }^{3}$ \\ 'Department of Medicine, Hjørring/Brønderslev Hospital, DK-9800 Hjørring, Denmark: \\ ${ }^{2}$ Department of Nephrology, Aalborg Hospital, DK-9800, Aalborg, Denmark: ${ }^{3}$ Medi-Lab A/S, \\ DK1001 Copenhagen, Denmark
}

Submitted 1 February 1999: Accepted 12 August 1999

\begin{abstract}
Objective: To review and discuss the effect of $n-3$ polyunsaturated fatty acids (PUFA) from fish in the prevention and, primarily, in the treatment of coronary artery disease (CAD).

Design: Overview of the literature.

Setting: Denmark.

Results: There is good evidence that fish consumption may reduce the risk of CAD. Conclusions: Fish can be recommended to reduce the risk of CAD both in healthy subjects and in patients with a high risk of CAD or with documented CAD. The use of fish oil concentrates can not be recommended in general, but may be considered in patients after a myocardial infarction or in patients with hypertriglyceridaemia. An increased intake of $n-3$ polyunsaturated fatty acids from fish may have substantial implications for public health and health economy by decreasing the risk of coronary events and sudden cardiac death.
\end{abstract}

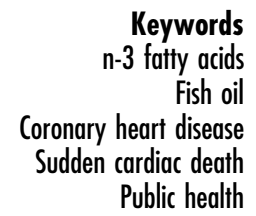

Keywords

Fish oil

Coronary heart disease Public health
In this paper we will discuss the evidence for a beneficial effect of long-chained n-3 PUFA, derived from fish, on the risk of CAD and the major cause of deaths in these patients, sudden cardiac death. We will focus on clinical trial data in patients with CAD and discuss the potential public health benefit from increasing the intake of $n-3$ PUFA from fish.

n-3 PUFA are members of an essential fatty acid family characterized by having their first double bond at carbon atom number 3, as opposed to the other essential fatty acid family n-6 PUFA whose first double bond is at carbon atom number 6 , counted from the methyl end of the carbon chain constituting the backbone of fatty acids ${ }^{1,2}$.

There are two subgroups of n-3 PUFA. One is $\alpha$ linolenic acid derived from plant oils (canola oil, rapeseed oil and linseed oil) composed of 18 carbon atoms and three double bonds (nomenclature 18:3). The other group of n-3 PUFA is derived from seafood, and the major marine n-3 PUFA are eicosapentaenoic acid (EPA; 20:5) and docosahexaenoic acid (DHA; 22:6). Because of a larger number of carbon atoms (20 and 22, respectively), these are also called longchained n-3 PUFA. $\alpha$-linolenic acid can to a limited extent be elongated and desaturated in humans to EPA and DHA, otherwise they are only aquired from seafood.
The content of n-3 PUFA varies between fish species $^{3}$, being high in fatty fish like mackerel and salmon and low in lean fish such as flounder and cod (Table 1). It is worth noting that the content of n-3 PUFA in seafood may vary considerably in relation to location and the time of year of capture ${ }^{3,4}$. The intake of longchained n-3 PUFA varies considerably between populations. It is very high in traditionally living Eskimos (10$\left.14 \mathrm{~g} \mathrm{day}^{-1}\right)$, low in western populations $\left(<0.2 \mathrm{~g} \mathrm{day}^{-1}\right)$ and intermediate in areas like Japan and Norway $(1-3 \mathrm{~g}$ $\mathrm{day}^{-1}$ ). The content of $\mathrm{n}-3$ PUFA in cod liver oil is about $20 \%$, and can be up to $90 \%$ in fish oil capsules.

\section{Marine n-3 PUFA, atherosclerosis and thrombosis}

n-3 PUFA are readily incorporated into human atherosclerotic plaques ${ }^{5}$. Considering the importance of plaque composition for future clinical events ${ }^{6,7}$, the effect of dietary n-3 PUFA on plaque characteristics is important, but has been scarcely studied. In a recent autopsy study it was reported that atherosclerosis was rare in Greenland Eskimos living on a traditional diet extremely rich in n-3 PUFA ${ }^{8}$. Advanced atherosclerosis was also less at necropsy in Alaskan Eskimos compared to other Alaskans eating less seafood ${ }^{9}$. Furthermore, pulse wave velocity of the aorta was slower (suggesting less atherosclerosis) in subjects living in Japanese 
Table 1 The approximate content of $n-3$ PUFA (g per $100 \mathrm{~g}$ of fish) in seafood (varies with season, place of capture, etc.)

\begin{tabular}{lc}
\hline Seafood & $\mathrm{n}-3$ PUFA \\
\hline Mackerel & $1.8-5.3$ \\
Herring & $1.2-3.1$ \\
Salmon & $1.0-2.0$ \\
Trout & $0.5-1.6$ \\
Tuna & $0.5-1.6$ \\
Halibut & $0.5-1.0$ \\
Shrimp & $0.2-0.4$ \\
Cod, plaice, flounder & c. 0.2 \\
\hline
\end{tabular}

fishing villages compared to people living in farming villages (and eating less fish) in Japan ${ }^{10}$.

A beneficial effect of marine n-3 PUFA on atherogenesis is also supported from the majority of animal studies showing that feeding with fish oil decreases atherosclerosis ${ }^{11}$. n-3 PUFA may also reduce thrombogenesis and thereby decrease the risk of thrombotic complications to plaque rupture/fissure. Thus, Hornstra has shown an antithrombotic effect of n-3 PUFA in rats, in particular when n-3 PUFA were given in combination with a diet low in saturated $\mathrm{fat}^{12}$. Cod liver oil reduced platelet deposition to carotid arteries subjected to deep intimal injury by balloon angioplasty in pigs and reduced injury-related vasoconstriction ${ }^{13}$. Also, when blood obtained from cod liver oil-treated pigs perfused normal pig aortas, platelet deposition to the aortas was lower than when blood from control pigs was used. These results indicate a beneficial effect of $n-3$ PUFA on the platelet-vessel wall interaction ${ }^{13}$. In a comprehensive study in baboons, a very high dose of fish oil was fed for 22 weeks $^{14}$. Femoral arteriovenous Dacron shunts were surgically implanted, and thrombotic responses of blood to segments of the grafts were studied. Later, endarterectomies were performed on carotid arteries. Vascular thrombus formation and lesions were inhibited by n-3 PUFA. These results fit with a reduction in microthrombi over atherosclerotic lesions found in hyperlipidaemic swine fed fish oil ${ }^{15}$.

Overall, there is some evidence that intake of $n-3$ PUFA may be antiatherogenic and antithrombotic.

\section{Marine n-3 PUFA and risk factors for CAD}

The risk of CAD depends on inherited genetic traits, age and gender. Known modifiable risk factors for CAD include tobacco smoking, hypertension, adipositas, high plasma levels of low-density-lipoprotein (LDL) cholesterol and low levels of high-density-lipoprotein (HDL) cholesterol, while the impact of hypertriglyceridaemia on cardiac risk is controversial ${ }^{16,17}$. High levels of plasma homocysteine, fibrinogen and of coagulation factor VII as well as impaired fibrinolysis are also associated with an increased risk of $\mathrm{CAD}^{16,17}$. Several other risk factors for CAD have been proposed, and the above mentioned is not a complete listing of risk factors.

The effect of n-3 PUFA on risk factors for CAD has been investigated in many studies. While dietary $n-3$ PUFA in practical doses - in contrast to common public belief - have no effect on LDL cholesterol levels, they do slightly increase the antiatherogenic $\mathrm{HDL}_{2}$ cholesterol and substantially decrease plasma triglycerides $^{1,18,19}$. n-3 PUFA may also decrease blood pressure by $2-5 \mathrm{mmHg}^{20,21}$. Most studies have indicated no effect of n-3 PUFA on plasma fibrinogen and coagulant factor VII levels ${ }^{1,2}$, but $n-3$ PUFA do reduce platelet reactivity and may impair fibrinolysis ${ }^{2}$. Other potential effects of n-3 PUFA, with respect to preventing atherosclerosis and thrombosis by modifying risk factors for CAD, include a reduction in leukocyte reactivity, an improvement of vessel wall function and a beneficial effect on blood rheology ${ }^{2,22,23}$. The biochemical effects of n-3 PUFA are usually seen after daily doses of between 2 and $5 \mathrm{~g}$, but these effects are dosedependent and the most favourable effects are achieved with high doses of n-3 PUFA. There is limited evidence that n-3 PUFA may reduce some of the health problems caused by smoking ${ }^{24,25}$, but this clearly needs further documentation.

The concept of assessing the individual risk of CAD as the sum of risk factors, instead of focusing on single risk factors such as high plasma cholesterol, is very important and has been stressed in the recently published European guidelines on the prevention of $\mathrm{CAD}^{17} . \mathrm{n}-3$ PUFA induce several beneficial changes in risk factors (Table 2), which in our view makes n-3 PUFA very attractive in the prophylaxis and treatment of the multifactorial disease, CAD.

\section{Primary prevention of CAD}

There is no randomized clinically controlled trial that has investigated an increased intake of n-3 PUFA (fish or $n-3$ PUFA supplements) in the primary prevention of CAD. Unfortunately, it is unlikely there will ever be such a trial, due to the costs involved and the nonpatentability of seafood (and fish oil capsules) making funding unrealistic, as no pharmaceutical company is

Table 2 Major beneficial effects of $n-3$ PUFA in CAD

\begin{tabular}{ll}
\hline Triglycerides & $\downarrow$ \\
$\mathrm{HDL}_{2}$ cholesterol & $\uparrow$ \\
Platelet reactivity & $\downarrow$ \\
Monocyte reactivity & $\downarrow$ \\
Neutrophil reactivity & $\downarrow$ \\
Blood pressure & $\downarrow$ \\
Improvement of blood rheology \\
Improvement of vasoreactivity \\
Antiarrhythmic properties
\end{tabular}

$\uparrow$, increase; $\downarrow$, decrease. 
going to finance such a trial. However, there is some evidence from epidemiological data that ingestion of marine n-3 PUFA reduces the risk of CAD. This has most clearly been shown in Greenland Eskimos ${ }^{26}$, but a low occurrence of CAD has also been reported in Alaskan Eskimos ${ }^{9}$. In studies from Japan the incidence of CAD was lower in fishing villages compared to farming villages with a lower intake of fish ${ }^{10,27}$. The possible association between consumption of seafood and $\mathrm{CAD}$ has also been studied in western populations with an average intake of $\mathrm{n}-3$ PUFA below $1 \mathrm{~g} \mathrm{day}^{-1}$. In Zutphen, a Dutch area included in the classic Seven Countries Study, an inverse correlation between fish consumption and CAD was reported in middle-aged men during 20 years of follow up ${ }^{28}$. A similar inverse correlation between heart disease and fish consumption in Caucasian populations was reported by some ${ }^{29-34}$, but not by other investigators ${ }^{23,35-40}$. In the Health Professionals Follow-up Study there was an unexplained increased risk of coronary artery bypass surgery grafting in men with higher fish consumption ${ }^{40}$. Finally, it is of interest that while fish consumption in the Physician's Health Study offered no protection against cardiovascular mortality ${ }^{35}$, total mortality and the risk of sudden cardiac death were indeed reduced in those who ate fish ${ }^{41}$. It is puzzling why an intake of fish (and n-3 PUFA) of this order of magnitude may offer protection against $\mathrm{CAD}$, because the beneficial biochemical effects of $n-3$ PUFA mentioned previously have not been shown at this low dosage ${ }^{1,2}$. The possibility that other components in fish might be contributing to this effect therefore should be kept in mind.

We would, however, like to stress that epidemiological data can neither prove nor reject the hypothesis of a beneficial effect of $n-3$ PUFA in the prevention of CAD.

\section{Clinical studies in patients with CAD}

Patients with established CAD have a substantially increased risk of future coronary events ${ }^{17}$. This patient population should therefore be given high priority and be treated vigorously.

\section{Angina pectoris}

Saynor et al. in 1984 reported a marked symptomatic effect (fewer anginal attacks and reduced consumption of glyceryl trinitrate) in 12 patients with stable angina pectoris supplemented with $6 \mathrm{~g} n-3$ PUFA per day for 9 months in an open trial ${ }^{42}$. We were, however, unable to confirm this in a controlled trial ${ }^{43}$, where 36 patients were randomized to 12 weeks' treatment with $4.5 \mathrm{~g} \mathrm{n}-3$ PUFA per day or matching placebo. Other studies on small groups of patients with stable angina have also been negative ${ }^{2}$.
No studies have been published on the effect of $n-3$ PUFA in patients with unstable angina pectoris.

Secondary prevention after myocardial infarction Burr et al. ${ }^{44}$ randomized approximately 2000 men with a recent myocardial infarction to various dietary changes including an increased intake of n-3 PUFA (fatty fish twice weekly or, alternatively, fish oil capsules) for 2 years. There was a significant 29\% reduction in total mortality and deaths from CAD in the group increasing their dietary intake of n-3 PUFA to $0.5-1 \mathrm{~g} \mathrm{day}^{-1}$ by eating fish or taking supplements with fish oil. The number of non-fatal infarctions increased, although not significantly, in the group given fish advice. This makes the underlying mechanism of protection in the fish group unlikely to be antithrombotic, and the authors suggested an antiarrhythmic effect of n-3 PUFA as an explanation for their findings. This study was a clinical landmark trial and still provides the best evidence for a protective role of $n-3$ PUFA in CAD.

In the more recent Lyon study, the effect of a Mediterranean type of diet with an increased intake of fish, bread, fruit, vegetables and $\alpha$-linolenic acid was investigated in 600 patients with a recent myocardial infarction ${ }^{45}$. There was a $70 \%$ reduction in morbidity and mortality in the patients randomized to the Mediterranean diet. However, in this trial an increased intake of fish was only one of several dietary changes, making it impossible to know what role the (marginally) increased intake of marine n-3 PUFA had on the outcome.

In a trial from India, 360 patients with suspected myocardial infarction were randomized to daily supplementation with approximately $1.1 \mathrm{~g}$ of $\mathrm{n}-3$ PUFA, $2.9 \mathrm{~g}$ of $\alpha$-linolenic acid or placebo ${ }^{46}$. Cardiac events were significantly reduced after 1 year with both the active treatments compared to the placebo, but cardiac deaths were only reduced in the fish oil group.

A large study from Italy (Gruppo Italieno per lo Studio della Sopravvivenza nell' Infarto Miocardioco: GISSI) was presented in March 1999 in New Orleans, USA at the 48th meeting of the American College of Cardiology. More than 11000 patients with CAD were randomized to daily supplementation with either one fish oil capsule containing approximately $0.85 \mathrm{~g}$ of $\mathrm{EPA}+\mathrm{DHA} ; 300 \mathrm{mg}$ of vitamin E; a combination of fish oil and vitamin E; or to placebo. After 3.5 years those randomized to fish oil had a $15-20 \%$ reduction in total mortality which was mainly due to an approximately $45 \%$ reduction in sudden cardiac death. In line with the results from the Diet and Reinfarction Trial (DART) there was no significant difference in non-fatal myocardial infarctions between the groups. The publication of this extremely important study is eagerly awaited. 


\section{Restenosis after PTCA}

A large proportion of patients treated for CAD with percutaneous transluminal coronary angioplasty (PTCA) develop restenosis. Accordingly, the effect of dietary n-3 PUFA in the prevention of restenosis has been evaluated in several trials. The results were initially promising with significant beneficial effects reported in five of eight randomized controlled trials and in a meta-analysis ${ }^{47}$. However, recent larger trials set up to finally prove this effect of n-3 PUFA on restenosis rate failed to do $\mathrm{so}^{48-50}$.

Nowadays, perhaps more than two-thirds of patients are treated with stents (metal frames that keep the vessel dilated) during PTCA, which has reduced the risk of restenosis. The studies with n-3 PUFA in the prevention of restenosis were all performed in the prestent era, and studies investigating the possible effect of n-3 PUFA in stented patients after PTCA have not yet been published.

\section{Coronary artery bypass surgery}

The incidence of late vein graft occlusion after coronary artery bypass surgery did not differ between patients randomized to fish oil or to aspirin ${ }^{51}$. However, in a study from Norway, 610 patients undergoing coronary artery bypass surgery were supplemented with $3.5 \mathrm{~g}$ n-3 PUFA daily as fish oil capsules or with placebo capsules for 1 year. Graft patency for venous, but not for arterial (mammary), grafts was significantly better after 1 year of follow-up in those randomized to fish oil $^{52}$.

\section{Arrbythmias and sudden cardiac death}

In a series of studies in rats and monkeys McLennan et al. have convincingly shown that dietary n-3 PUFA reduce the incidence and severity of malignant ventricular tachyarrhythmias after coronary artery ligation and during reperfusion ${ }^{53,54}$. Why n-3 PUFA protect against malignant tachyarrhythmias remains to be established, but several mechanisms have been proposed:

1. Changes in the formation of eicosanoids ${ }^{53}$. Several studies have shown that an increase in the prostacyclin/ thromboxane balance may protect against arrhythmias 55 .

2. A reduction of calcium flux across cell membranes ${ }^{56}$. 3. A modulating effect of n-3 PUFA on $\beta$-receptors ${ }^{57}$.

4. A blockade of potassium channels by n-3 PUFA ${ }^{58}$.

It is likely that these and perhaps other mechanisms as well may act in concert ${ }^{59}$. This may involve a common pathway, namely a change in the (patho)physiological function of cell membranes induced by alteration in their lipid composition as found after an increased intake of n-3 PUFA.

Human studies lend support to an antiarrhythmic effect of n-3 PUFA. Thus, the content of long-chained n-3 PUFA in coronary arteries was lower in subjects dying from sudden cardiac death than in controls dying of other causes ${ }^{60}$, and intake of n-3 PUFA was associated with a reduced risk of cardiac arrest in previously healthy subjects ${ }^{61}$. Furthermore, as previously mentioned in the Physician's Health Study the risk of sudden cardiac death was reduced by fish consumption ${ }^{41}$. Also, a reduction in ventricular extrasystoles has been reported from small studies in humans eating n-3 PUFA ${ }^{62,63}$. Heart rate variability is, however, a better indicator for the risk of sudden cardiac death than the number of ventricular extrasystoles $^{64}$. An increased heart rate variability indicates a beneficial alteration in cardiac vagal tone ${ }^{64}$, that may relate to the experimental findings with n-3 PUFA discussed above. We therefore believe it is of major interest that our group has found that n-3 PUFA increase heart rate variability in patients with CAD, patients with renal failure and healthy men ${ }^{65-68}$. Our studies thus suggest that the major cause of death from CAD, sudden cardiac death, may be reduced by dietary n-3 PUFA.

\section{Coronary anatomy}

As previously stated there is some epidemiological evidence for less coronary atherosclerosis in populations with a high intake of fish $^{8-10}$ and for less atherosclerosis in animals fed n-3 PUFA ${ }^{11}$. Furthermore, case-control studies have suggested an inverse correlation between coronary atherosclerosis and the content of $n-3$ PUFA in various tissues ${ }^{60,69}$.

Two clinical trials have evaluated the effect of $n-3$ PUFA on regression/progression of atherosclerosis in patients with proven $\mathrm{CAD}^{70,71}$. In the first study treatment with $6 \mathrm{~g}$ n-3 PUFA per day for 2 years to 31 patients with CAD did not promote beneficial effects on coronary atherosclerosis compared to a group of 28 patients given placebo ${ }^{70}$. However, in a larger trial of 223 patients, those randomized to $1.6 \mathrm{~g}$ n-3 PUFA daily for 2 years had a borderline significant beneficial effect on coronary atherosclerosis compared to patients receiving placebo ${ }^{71}$.

\section{Types and safety of n-3 PUFA}

Seafood is the natural source of long-chained n-3 PUFA. Lean fish provides low amounts of $n-3$ PUFA, but contains little saturated fat and cholesterol and can be recommended for reducing the risk of CAD. Fatty fish have a lower content of saturated fat than some servings containing meat and may for this reason, independent of likely beneficial effects of n-3 PUFA, be a better food source.

The concept of substituting fish for other food sources, and not just adding fish oil supplements to the habitual diet, must be emphasized. If fish oils are to 
be used, products of high quality should be chosen with declared amounts of EPA and DHA, and with added antioxidants.

Concern has been expressed about an increased consumption of fish due to intake of heavy metals and pesticides from contaminated fish ${ }^{72}$. The risk is low, but must not be neglected, and pollution of the sea and its fish should be monitored by international organizations. During industrial processing it is possible to remove toxic substances from fish oil concentrates.

PUFA (including n-3 PUFA) are susceptible to oxidation. This may be very important, because of the probable pivotal role of oxidation of LDL in atherogenesis $^{73}$. Epidemiological data do not, however, suggest increased atherosclerosis in fish consumers. Whether an increased intake of n-3 PUFA leads to a clinically relevant enhanced in vivo oxidation of LDL is debatable ${ }^{74,75}$. Anyway, oxidation of n-3 PUFA in fish oil concentrates should be minimized before their intake, which can be achieved by the addition of antioxidants (vitamin E), proper storage and encapsulation.

There has also been concern about an increased risk of bleeding, especially after consumption of larger doses of fish oil concentrates, but there is very little clinical evidence in support of this ${ }^{76-78}$. It has been claimed, based on limited data, that n-3 PUFA may deteriorate glycaemic control in patients with diabetes, but recent data have discarded this hypothesis ${ }^{21,79,80}$. While immune responses may be reduced by n-3 PUFA, there is no evidence that intake of $n-3$ PUFA is associated with an increased risk of cancer or serious infections $s^{1,2,78}$.

\section{Public health implications}

As our understanding of the atherosclerotic process progresses, one thing becomes more and more clear, namely that atherosclerosis is due to a maladaptation of fundamental protective systems evolved over the evolution of mammals (i.e. haemostasis, inflammation, etc.). Studies of the nutrition of humans have pointed out that drastic changes have taken place over the last 100-200 years, coinciding with the industrialization of our culture. During this timespan the consumption of saturated fats increased, following the increased ingestion of dairy products, hydrogenated oils and meat. In the same period dietary levels of n-3 PUFA diminished and those of n-6 PUFA increased ${ }^{81}$. Along with these changes CAD made its debut. In line with this, death from CAD has significantly decreased in western countries during the last decades probably partly due to a decreased intake of saturated fatty acids.

To generally recommend a reversion of dietary fat intake towards a composition more in harmony with that of the long evolutionary period of humankind seems rather straightforward and with few risks of unwanted side effects. Along this line we would like to point to a study from Iceland, a country with a population characterized by high fish and n-3 PUFA consumption and a long life expectancy ${ }^{82}$. The investigation was a comparative study of cardiovascular risk factors in two genetically comparable, but geographically and culturally separated, populations - an Icelandic and an Islandic-Canadian one. The mortality rates for CAD were significantly higher in the latter population than in the Icelandic population in spite of higher levels of the major risk factor for CAD, serum total cholesterol (LDL cholesterol), in the Islandic population. The Islandic population had, however, lower levels of n-6 PUFA and three times higher levels of n-3 PUFA in their plasma phospholipids $^{82}$. The Icelanders hold the European record for fish consumption $\left(73 \mathrm{~g} \mathrm{day}^{-1}\right.$ person $\left.^{-1}\right)$, and the use of cod liver oil as a food supplement is widespread. The findings seem to indicate that an increased consumption of n-3 PUFA may be cardioprotective in the context of an otherwise atherogenic diet. It has been argued that people would accrue measurable benefits by increasing dietary intake of $\mathrm{n}-3$ PUFA to $1-2 \mathrm{~g} \mathrm{day}{ }^{-1}$, which is far above the average daily estimated intake of $0.1-0.2 \mathrm{~g}$ long-chained n-3 PUFA in most industrialized nations ${ }^{83}$.

Not many countries have yet translated this issue into specific dietary recommendations. However, in Canada official recommendations including sex- and agedependent values were issued in 1990 regarding the intake of n- 6 and n-3 PUFA ${ }^{84}$, and in the UK an intake of 8-10 g EPA + DHA per week (2-3 medium servings of oil-rich fish) has been recommended ${ }^{85}$.

The importance of sudden cardiac death for public health is illustrated from a recent British study reporting that $74 \%$ of fatal events among patients with heart disease happened outside hospital ${ }^{86}$. Any substantial decrease in coronary deaths can therefore only be obtained by reducing CAD or by preventing its complication of sudden cardiac death. In-hospital mortality from CAD is around $15 \%^{86}$, and even a total elimination of these fatalities will only have a minor effect on total cardiac mortality. Add to this that many patients die from sudden cardiac death as their first symptom of CAD. Over the years clinical trials with expensive pharmacotherapy to prevent arrhythmic death after myocardial infarction have shown disappointing results and even deleterious effects ${ }^{87}$.

Dietary measures should therefore be included in the search for prevention of one of the most common causes of death in the western world, sudden cardiac death. Results obtained so far suggest that sudden cardiac death may be reduced by higher intakes of $n-3$ PUFA.

\section{Conclusions}

Data from epidemiological studies, animal experiments and clinical trials in humans lend support for a 
beneficial role of $n-3$ PUFA on CAD. Effects of $n-3$ PUFA may be mediated through several mechanisms. Among these are: (i) a reduction in leukocyte and platelet reactivity; (ii) an improvement of the lipid profile; (iii) an improvement of vessel wall characteristics; (iv) a decrease in blood pressure; (v) an improvement of blood rheology; and (vi) an antiarrhythmic effect.

Further clinical studies with substitution/supplementation with n-3 PUFA to patients with acute myocardial ischaemia, previous myocardial infarction, patients undergoing coronary artery bypass surgery, patients with arrhythmias and patients at high risk of CAD should be undertaken, because only results from controlled clinical trials can establish whether n-3 PUFA reduce the risk of CAD. It is important to be aware that only studies with hard end points (total mortality, mortality from CAD and mortality from cardiovascular disease) are likely to have an impact on the treatment modalities chosen by clinicians. Such studies must be randomized, controlled and include many patients.

If the published results from the GISSI trial confirm the orally presented data as expected, we believe that all patients with CAD should increase their intake of n-3 PUFA (fish or fish oil capsules) to approximately $0.85 \mathrm{~g} \mathrm{day}^{-1}$. In the meantime, we advocate the incorporation of fish in the diet of healthy subjects and in particular to patients with or at high risk for CAD. This is in line with the recommendations of a recently published expert workshop summary ${ }^{88}$.

\section{Acknowledgements}

This paper is based on studies financially supported by Speciallæge Heinrich Kopps Legat and The Medical Research Foundation of the County of Northern Jutland.

\section{References}

1 Schmidt EB, Dyerberg J. Omega-3 fatty acids: current status in cardiovascular medicine. Drugs 1994; 47: 405-24.

2 Schmidt EB. n-3 fatty acids and the risk of coronary heart disease. Dan. Med. Bull. 1997; 44: 1-22.

3 Hepburn FN, Exler J, Weihrauch JL. Provisional tables on the content of omega-3 fatty acids and other fat components of selected foods. J. Am. Diet. Assoc. 1986; 86: 788-93.

4 Soriguer F, Serns S, Valverde E, et al. Lipid, protein, and calorie content of different Atlantic and Mediterranean fish, shellfish, and molluscs commonly eaten in the south of Spain. Eur. J. Epidemiol. 1997; 13: 451-63.

5 Rapp JH, Connor WE, Lin DS, Porter JM. Dietary eicosapentaenoic acid and docosahexaenoic acid from fish oil. Their incorporation into advanced human atherosclerotic plaques. Arterioscler. Thromb. 1991; 11: 903-11.

6 Fuster V, Badimon L, Badimon JJ, Chesebro JH. The pathogenesis of coronary artery disease and the acute coronary syndromes. N. Engl. J. Med. 1992; 326: 242-50, 310-18.
7 Davies MJ. Stability and instability: two faces of coronary atherosclerosis. Circulation 1996; 94: 2013-20.

8 Mulvad G, Pedersen HS, Jul E, et al. Atherosclerosis in Greenland natives. An autopsy study. Poster presented at the Ninth International Congress on Circumpolar Health, Reykjavik, Iceland, 20-25 June 1993.

9 Newman III WP, Propst MT, Middaugh JP. Atherosclerosis in Alaska natives and non-natives. Lancet 1993; 341: 1056-7.

10 Hamazaki T, Urakaze M, Sawazaki S, Yamazaki K, Taki H, Yano S. Comparison of pulse wave velocity of the aorta between inhabitants of fishing and farming villages in Japan. Atherosclerosis 1988; 73: 157-60.

11 Soei LK, Lamers JMJ, Sassen LMA, et al. Fish oil: a modulator of experimental atherosclerosis in animals. In: Kristensen SD, Schmidt EB, De Caterina R, Endres S, eds. n-3 Fatty Acids: Prevention and Treatment of Vascular Disease. Springer Verlag: Bi \& Gi Publishers, 1995; 55-75.

12 Hornstra G. The significance of fish and and fish-oil enriched food for prevention and therapy of cardiovascular disease. In: Vergroesen A, Crawford M, eds. The Role of Fats in Human Nutrition. London: Academic Press, 1989; $152-$ 235.

13 Lam JYT, Badimon JJ, Ellefson RD, Fuster V, Chesebro JH Cod liver oil alters platelet-arterial wall response to injury in pigs. Circ. Res. 1992; 71: 769-75.

14 Harker LA, Kelly AB, Hanson SR, et al. Interruption of vascular thrombus formation and vascular lesion formation by dietary $n-3$ fatty acids in fish oil in nonhuman primates. Circulation 1993; 87: 1017-29.

15 Kim D, Schmee J, Baker JE, et al. Dietary fish oil reduces microthrombi over atherosclerotic lesions in hyperlipidemic swine even in the absence of plasma cholesterol reduction. Exp. Mol. Pathol. 1993; 59: 122-35.

16 National Cholesterol Education Program. Second report of the expert panel on detection, evaluation, and treatment of high blood cholesterol in adults (ATP II). Circulation 1994; 89: $1329-445$.

17 Wood D, De Backer G, Faergeman O, Graham I, Mancia G, Pyorala K. Prevention of coronary heart disease in clinical practice. Eur. Heart J. 1998; 19: 1434-503.

18 Schmidt EB, Kristensen SD, De Caterina R, Illingworth DR. The effects of $n-3$ fatty acids on plasma lipids and lipoproteins and other cardiovascular risk factors in patients with hyperlipidemia. Atherosclerosis 1993; 103: 107-21.

19 Harris WS. n-3 fatty acids and lipoproteins: comparison of results from human and animal studies. Lipids 1996; 31: $243-52$.

20 Morris MC, Sacks F, Rosner B. Does fish oil lower blood pressure? Circulation 1993; 88: 523-33.

21 Toft I, Bønaa KH, Ingebretsen OC, Nordøy A, Jenssen T Effects of $n-3$ polyunsaturated fatty acids on glucose homeostasis and blood pressure in essential hypertention. Ann. Intern. Med. 1995; 123: 911-18.

22 Ernst E. Effects of n-3 fatty acids on blood rheology. J. Intern Med. 1989; 225 (Suppl. 1): 129-32.

23 Goode GK, Garcia S, Heagerty AM. Dietary supplementation with marine fish oil improves in vitro small artery endothelial function in hypercholesterolemic patients. Circulation 1997; 96: 2802-7.

24 Rodriquez BL, Sharp DS, Abbott RD, et al. Fish intake may limit the increase in risk of coronary heart disease morbidity and mortality among heavy smokers. Circulation 1996; 94 952-6.

25 Shahar E, Folsom AR, Melnick SL, et al. Dietary n-3 polyunsaturated fatty acids and smoking-related chronic obstructive pulmonary disease. N. Engl. J. Med. 1994; 331 $228-33$

26 Bjerregaard P, Dyerberg J. Mortality from ischaemic heart disease and cerebrovascular disease in Greenland. Int. J. Epidemiol. 1988; 17: 514-19. 
27 Kagawa Y, Nishizawa M, Suzuki M, et al. Eicosapolyenoic acids of serum lipids of Japanese islanders with low incidence of cardiovascular diseases. J. Nutr. Sci. Vitaminol. 1982; 28: 441-53.

28 Kromhout D, Bosschieter EB, Coulander CDL. The inverse relation between fish consumption and 20-year mortality from coronary heart disease. N. Engl. J. Med. 1985; 312: 1205-9.

29 Kromhout D, Feskens EJM, Bowles CH. The protective effect of a small amount of fish on coronary heart disease mortality in an elderly population. Int. J. Epidemiol. 1995; 24: 340-5.

30 Daviglus ML, Stamler J, Orencia AJ, et al. Fish consumption and the 30-year risk of fatal myocardial infarction. N. Engl.J. Med. 1997; 336: 1046-53.

31 Norell SE, Ahlbom A, Feychting M, et al. Fish consumption and mortality from heart disease. BMJ 1986; 293: 426.

32 Gramenzi A, Gentile A, Fasoli M, et al. Association between certain foods and risk of acute myocardial infarction in women. BMJ 1990; 300: 771-3.

33 Dolecek TA, Grandits G. Dietary polyunsaturated fatty acids and mortality in the multiple risk factor intervention trial (MRFIT). World Rev. Nutr. Diet. 1991; 66: 205-16.

34 Feskens EJM, Bowles CH, Kromhout D. Association between fish intake and coronary heart disease mortality. Diabetes Care 1993; 16: 1029-34.

35 Morris MC, Manson JAE, Rosner B, Buring JE, Willett WC, Hennekens $\mathrm{CH}$. Fish consumption and cardiovascular disease in the Physician's Health Study: a prospective study. Am. J. Epidemiol. 1995; 142: 166-75.

36 Crombie IK, McLoone P, Smith WCS, et al. International differences in coronary heart disease mortality and consumption of fish and other foodstuffs. Eur. Heart J. 1987; 8: 560-3.

37 Vollset SE, Heuch I, Bjelke E. Fish consumption and coronary heart disease. N. Engl.J. Med. 1985; 313: 820-1.

38 Lapidus L, Andersson H, Bengtsson C, et al. Dietary habits in relation to incidence of cardiovascular disease and death in women: a 12 -year follow-up of participants in the population study of women in Gothenburg, Sweden. Am. J. Clin. Nutr. 1986; 44: 444-8.

39 Simonsen T, Vårtun A, Lyngmo V, et al. Coronary heart disease, serum lipids, platelets and dietary fish in two communities in northern Norway. Acta Med. Scand. 1987; 222: $237-45$.

40 Ascherio A, Rimm EB, Stampfer MJ, Giovannucci EL, Willett WC. Dietary intake of marine $\mathrm{n}-3$ fatty acids, fish intake, and the risk of coronary disease among men. N. Engl. J. Med. 1995; 332: 977-82.

41 Albert CM, Hennekens CH, O'Donnell CJ, et al. Fish consumption and risk of sudden cardiac death. JAMA 1998; 279: 23-8.

42 Saynor R, Verel D, Gillott T. The long term effect of dietary supplementation with fish lipid concentrate on serum lipids, bleeding time, platelets and angina. Atherosclerosis 1984; 50: 3-10.

43 Kristensen SD, Schmidt EB, Andersen HR, Dyerberg J. Fish oil in angina pectoris. Atherosclerosis 1987; 64: 13-19.

44 Burr ML, Fehily AM, Gilbert JF, et al. Effects of changes in fat, fish, and fibre intakes on death and myocardial reinfarction: Diet and Reinfarction Trial (DART). Lancet 1989; ii: 757-61.

45 De Lorgeril M, Renaud S, Mamelle N, et al. Mediterranean alpha-linolenic acid-rich diet in secondary prevention of coronary heart disease. Lancet 1994; 343: 1454-9.

46 Singh RB, Niaz MA, Sharma JP, Kumar R, Rastogi V, Moshiri M. Randomized, double-blind, placebo-controlled trial of fish oil and mustard oil in patients with suspected acute myocardial infarction: the Indian experiment of infarct survival - 4. Cardiovasc. Drugs Ther. 1997; 11: 485-91.

47 Gapinski JP, VanRuiswyk JV, Heudebert GR, Schectman GS.
Preventing restenosis with fish oils following coronary angioplasty. A meta-analysis. Arch. Intern. Med. 1993; 153: 1595-601.

48 Cairns JA, Gill J, Morton B, et al. Fish oils and low-molecularweight heparin for the reduction of restenosis after percutaneous transluminal coronary angioplasty. Circulation 1994; 94: 1553-60.

49 Leaf A, Jorgensen MB, Jacobs AK, et al. Do fish oils prevent restenosis after coronary angioplasty? Circulation 1994; 90 : 2248-57.

50 Johansen O, Brekke M, Seljeflot I, Abdelnoor M, Arnesen H. n-3 fatty acids do not prevent restenosis after coronary angioplasty: results from the CART study. J. Am. Coll. Cardiol. 1999; 33: 1619-26.

51 Roy L, Meyer F, Gingras L, Auger L. A double-blind randomized controlled study comparing the efficacy of fish oil and low dose ASA to prevent coronary saphenous vein graft obstruction after CABG. Circulation 1991; 84 (Suppl. II): II-285.

52 Eritsland J, Arnesen H, Grønseth K, Fjeld NB, Abdelnoor M. Effect of dietary supplementation with n-3 fatty acids on coronary artery bypass graft patency. Am. J. Cardiol. 1996; 77: 31-6.

53 Charnock JS, McLennan PL, Abeywardena MY. Dietary modulation of lipid metabolism and mechanical performance of the heart. Mol. Cell. Biochem. 1992; 116: 19-25.

54 McLennan PL. Relative effects of dietary saturated, monounsaturated, and polyunsaturated fatty acids on cardiac arrhythmias in rats. Am. J. Clin. Nutr. 1993; 57: 207-12.

55 Nair SSD, Leitch JW, Falconer J, Garg ML. Prevention of cardiac arrhythmia by dietary (n-3) polyunsaturated fatty acids and their mechanism of action. J. Nutr. 1997; 127: 38393.

56 Hallaq H, Smith TW, Leaf A. Modulation of dihydropyridinesensitive calcium channels in heart cells by fish oil fatty acids. Proc. Natl. Acad. Sci. USA 1992; 89: 1760-4.

57 Kang JX, Leaf A. Prevention and termination of betaadrenergic agonist-induced arrhythmias by free polyunsaturated fatty acids in neonatal rat cardiac myocytes. Biochem. Biophys. Res. Commun. 1995; 208: 629-36.

58 Garratt JC, McEnvoy MP, Owen DG. Blockade of two voltage-dependent potassium channels, $\mathrm{mKv} 1.1$ and $\mathrm{mKv}$ 1.2, by docosahexaenoic acid. Eur. J. Pharmacol. 1996; 14: 393-6.

59 Kang JX, Leaf A. Antiarrhythmic effects of polyunsaturated fatty acids. Recent studies. Circulation 1996; 94: 1774-80.

60 Luostarinen R, Boberg M, Saldeen T. Fatty acid composition in total phospholipids of human coronary arteries in sudden cardiac death. Atherosclerosis 1993; 99: 187-93.

61 Siscovick DS, Raghunathan TE, King I, et al. Dietary intake and cell membrane levels of long-chain $\mathrm{n}-3$ polyunsaturated fatty acids and the risk of primary cardiac arrest. JAMA 1995; 274: 1363-7.

62 Christensen JH, Gustenhoff P, Ejlersen E, et al. n-3 fatty acids and ventricular extrasystoles in patients with ventricular tachyarrhythmias. Nutr. Res. 1995; 15: 1-8.

63 Sellmayer A, Witzgall H, Lorenz RL, Weber PC. Effects of dietary fish oil on ventricular premature complexes. Am.J. Cardiol. 1995; 76: 974-7.

64 Task Force of the European Society of Cardiology and the North American Society of Pacing and Electrophysiology. Heart rate variability. Standards of measurement, physiological interpretation, and clinical use. Circulation 1996; 93: 1043-65.

65 Christensen JH, Gustenhoff P, Korup E, et al. Effect of fish oil on heart rate variability in survivors of myocardial infarction: a double blind randomised controlled trial. BMJ 1996; 312: 677-8.

66 Christensen JH, Korup E, Aarøe J, et al. Fish consumption, $\mathrm{n}-3$ fatty acids in cell membranes, and heart rate variability 
in survivors of myocardial infarction with left ventricular dysfunction. Am. J. Cardiol. 1997; 79: 1670-3.

67 Christensen JH, Aarøe J, Knudsen N, et al. Heart rate variability and $\mathrm{n}-3$ fatty acids in patients with chronic renal failure - a pilot study. Clin. Nephrol. 1998; 49: 102-6.

68 Christensen JH, Christensen MS, Dyerberg J, Schmidt EB. Fatty acids in blood cell membranes is related to heart rate variability. A dose-response study with n-3 fatty acids. Am. J. Clin. Nutr. 1999; 70: 331-7.

69 Seidelin KN, Myrup B, Fischer-Hansen B. n-3 fatty acids in adipose tissue and coronary artery disease are inversely related. Am. J. Clin. Nutr. 1992; 55: 1117-19.

70 Sacks FM, Stone PH, Gibson M, Silverman DI, Rosner B, Pasternak RC. Controlled trial of fish oil for regression of human coronary atherosclerosis. J. Am. Coll. Cardiol. 1995; 25: $1492-8$.

71 Von Schacky C, Angerer P, Kothny W, Theisen K, Mudra H. The effect of dietary omega- 3 fatty acids on coronary atherosclerosis. A randomized, double-blind, placebo-controlled trial. Ann. Intern. Med. 1999; 130: 554-62.

72 Salonen JT, Seppänen K, Nyyssönen K, et al. Intake of mercury from fish, lipid peroxidation, and the risk of myocardial infarction and coronary, cardiovascular, and any death in eastern Finnish men. Circulation 1995; 91: 645-55.

73 Witzkum JL, Steinberg D. Role of oxidized low density lipoprotein in atherogenesis. J. Clin. Invest. 1991; 88: 1785-92.

74 Suzukawa M, Abbey M, Howe PR, Nestel PJ. Effect of fish oil fatty acids on low density lipoprotein size, oxidizability, and uptake by macrophages. J. Lipid Res. 1995; 36: 473-84.

75 Brude IR, Drevon CA, Hjermann I, et al. Peroxidation of LDL from combined-hyperlipidemic male smokers supplied with $\omega-3$ fatty acids and antioxidants. Arterioscler. Thromb. Vasc. Biol. 1997; 17: 2576-88.

76 Smith $\mathrm{P}$, Arnesen $\mathrm{H}$, Opstad T, et al. Influence of highly concentrated n-3 fatty acids on serum lipids and hemostatic variables in survivors of myocardial infarction receiving either oral anticoagulants or matching placebo. Thromb. Res. 1989; 53: 467-74.
77 Bender NK, Kraynak MA, Chiquette E, Linn WD, Clark GM, Bussey HI. Effects of marine fish oils on the anticoagulation status of patients receiving chronic warfarin therapy. $J$. Thromb. Thrombolys. 1998; 5: 257-61.

78 Schmidt EB, Møller JM, Svaneborg N, Dyerberg J. Safety aspects of fish oils. Drug Invest. 1994; 7: 215-20.

79 Sirtori CR, Paoletti R, Mancini M, et al. n-3 fatty acids do not lead to an increased diabetic risk in patients with hyperlipidemia and abnormal glucose tolerance. Am. J. Clin. Nutr. 1997; 65: 1874-81.

80 Friedberg, Janssen MJFM, Heine RJ, Grobbee DE. Fish oil and glycemic control in diabetes. A meta-analysis. Diabetes Care 1998; 21: 494-500.

81 Weber PC. Clinical studies on the effect of n-3 fatty acids on cells and eicosanoids in the cardiovascular system. J. Intern. Med. 1989; 225 (Suppl. 1): 61-8.

82 Skuladottir GV, Gudmundsdottir S, Olafsson GB, et al. Plasma fatty acids and lipids in two separate, but genetically comparable, Icelandic populations. Lipids 1995; 30: 649-55.

83 Newton IS. Global food fortification perspectives of longchained omega 3 fatty acids. In: Simopoulos AP, ed. The Return of Omega 3 Fatty Acids into the Food Supply. I. Landbased Animal Food Products and their Health Effects. Basel: Karger, 1998; 199-209.

84 Health and Welfare Canada. Nutrition Recommendations Ottawa: Minister of Supply and Services, 1990.

85 British Nutritional Foundation. Unsaturated Fatty Acids Nutritional and Physiological Significance. Report of the British Nutritional Foundation's Task Force. BNF, 1992.

86 Norris RM. Fatality outside hospital from acute coronary events in three British health districts, 1994-5. BMJ 1998; 316: 1065-70.

87 Barron HV, Viskin S. Autonomic markers and prediction of cardiac death after myocardial infarction. Lancet 1998; 351 $461-2$.

88 De Deckere EAM, Korver O, Verscheuren PM, Katan MB Health aspects of fish and $n-3$ polyunsaturated fatty acids from plant and marine origin. Eur. J. Clin. Invest. 1998; 52 $749-53$ 